\title{
PENGGUNAAN GAMBAR SEBAGAI ALAT PERAGA UNTUK MENINGKATKAN HASIL BELAJAR IPA SISWA KELAS V SD
}

\author{
Dedi Sulaeman, Muhammad Yusuf Saputro \\ Sekolah Pascasarjana Universitas Muhammadiyah Prof. DR. HAMKA, Jakarta
}

E-mail: sulaemandedi07@gmail.com

Receive: 02/01/2020

Accepted:05/03/2020

Published: 12/04/2020

\begin{abstract}
Abstrak
Mutu pendidikan tercermin dari mutu Sumber Daya Manusia ( SDM ). Sumber Daya Manusia masih rendah berarti mutu pendidikan pun masih rendah. Untuk meningkatkan mutu pendidikan maka kita dapat memulai dengan tenaga pendidik (guru) itu terlebih dahulu yang harus ditingkatkan mutunya.Untuk mempelajari IPA, anak - anak akan lebih mudah memahami konsep konsep yang rumit dan abstrak jika disertai contoh konkret.Contoh yang sesuai situasi dan kondisi yang dihadapi dengan mempraktikan sendiri upaya penemuan konsep melalui kegiatan fisik dan mental. Seperti penggunaan alat peraga. Penggunaan alat peraga pada pembelajaran IPA di SDN Babelan Kota 02 sangat tepat diterapkan untuk meningkatkan aktivitas dan hasil belajar siswa.Hasil penelitian menunjukan bahwa ada peningkatan hasil dan minat belajar siswa dengan menggunakan alat peraga. Hal tersebut dapat dilihat dari perolehan nilai di setiap siklus mengalami peningkatan, dilihat dengan persentase ketercapaian KKM dari Prasiklus sebesar 27\%, Siklus I 63,6\% dan Siklus II 100\%.
\end{abstract}

Kata Kunci: alat peraga gambar, hasil belajar, IPA

\begin{abstract}
English-Indonesia)
The quality of education is reflected in the quality of Human Resources (HR). Low Human Resources means that the quality of education is still low. To improve the quality of education, we can first start with the teaching staff (teachers) who must be upgraded. To study science, children will more easily understand complicated and abstract concepts if accompanied by concrete examples. Examples that fit the situation and conditions faced by practicing their own efforts to find concepts through physical and mental activities. Like the use of props. The use of teaching aids on natural science learning at SDN Babelan Kota 02 is very appropriate to be applied to improve student learning activities and outcomes. The results showed that there was an increase in student interest and learning outcomes by using teaching aids. This can be seen from the value acquisition in each cycle has increased, seen by the percentage of KKM achievement in Pre-Cycle dory by 27\%, Cycle $163.6 \%$ and Cycle II $100 \%$.
\end{abstract}

Keywords: Learning outcomes, picture practice tools, science. 



\section{Pendahuluan}

Mutu pendidikan tercermin dari mutu Sumber Daya Manusia (SDM). Sumber Daya Manusia masih rendah berarti mutu pendidikan pun masih rendah. Untuk meningkatkan mutu pendidikan maka kita dapat memulai dengan tenaga pendidik (guru) itu terlebih dahulu yang harus ditingkatkan mutunya. Seiring dengan perkembangan IPTEK, pengetahuan guru harus selalu disegarkan.

Berdasarkan dari pengalaman yang dialami oleh penulis yang sudah lima tahun mengajar pada kelas V di SDN Babelan Kota 02, Kecamatan Babelan Kabupaten Bekasi, menunjukan hasil yang tidak memuaskan, nilai pada mata pelajaran IPA khususnya pada materi alat pernapasan pada manusia, menunjukan hasil yang rendah hanya $35 \%$ siswa saja yang mencapai Kriteria Ketuntasan Minimal (KKM) yang telah ditentukan. Terdapat beberapa faktor baik dari guru, siswa, maupun situasi lingkungan belajar siswa, yang menyebabkan hasil belajar siswa rendah, siswa kurang aktif dalam proses pembelajaran, kurangnya alat peraga, guru kurang terampil menggunakan alat peraga dalam proses pembelajaran, penggunaan alat peraga pada diharapkan dapat meningkatkan hasil belajar siswa pada mata pelajaran IPA.

Menurut Oemar Hamalik (1986 : 43)

" Gambar adalah suatu yang berwujud dan dapat dinikmati visual secara langsung yang dapat mengungkapkan pikiran dan perasaan.Dari pendapat tersebut maka gambar dapat diartikan suatu bentuk tiruan yang dibuat untuk mengennal sesuatu dengan lebih konkrit.

"Satu gambar dapat memiliki seribu kata " seperti dituliskan oleh DePorter, Reardon dan Singer-Nourie (1999) bahwa dalam mengawali sebuah proses pembelajaran dapat manrik perhatian siswa secara visual dan dapat merangsang syaraf. Sedangkan alat peraga adalah sesuatu yang digunakan untuk belajar yang dapat menarik minat siswa untuk belajar, sehingga apa yang ingin disampaikan dalam proses belajar dapat tersampaikan dengan baik.Penggunaan alat peraga diharapkan dapat membantu meningkatkan hasil belajar siswa. Menurut Sujana (1995) hasil belajar adalah tingkat kemampuan dan kemajuan yang telah dicapai oleh siswa setelah proses pembelajaran dalam kurun waktu tertentu. Hasil belajar siswa pada mata pelajaran IPA di SD masih relatif rendah karena sumber dan bahan belajar yang digunakan tidak bervariasi. Pelajaran IPA itu sendiri merupakan ilmu pengetahuan yang didapat dari hasil kegiatan manusia yang diperoleh dengan menggunakan langkah-langkah ilmiah

Berdasarkan pengalaman mengajar di SDN Babelan Kota 02 di mana hasil pembelajaran khususnya pada pelajaran IPA hasilnya belum memuaskan, hal ini perlu mendapat perhatian dan penanganan khusus untuk meningkatkan hasil belajar siswa. Berdasarkan latar belakang yang telah diuraikan di atas, maka peneliti melakukan perbaikan proses pembelajaran melalui Penelitian Tindakan Kelas (PTK) yang berjudul "Penggunaan Gambar Sebagai Alat Peraga Untuk Meningkatkan Hasil Belajar Siswa Kelas V Sekolah Dasar".

\section{Metode}

Penelitian yang dilakukan oleh peneliti adalah Penelitian Tindakan Kelas (PTK). Yang menjadi subjek penelitian adalah siswa-siswi kelas V SDN Babelan Kota 02 Kecamatan Babelan Kabupaten Bekasi sebanyak 22 orang yang terdiri dari 10 siswa dan 12 siswi. Penelitian tindakan ini menggunakan siklus dimana setiap siklusnya meliputi perencanaan, pelaksanaan dan pengamatan serta refleksi dan diagnosis.

Untuk memperoleh data yang dibutuhkan penelitian ini menggunakan teknik observasi menggunakan instrumen lembar observasi dan hasil belajar siswa. Adapun perlengkapan yang digunakan adalah lembar observasi untuk mengamati aktivitas siswa dalam pembelajaran IPA 
Jurnal Edumaspul, 4 (2), 202 - 344

(Dedi Sulaeman, Muhammad Yusuf Saputro)

kelas V di SDN Babelan Kota 02 Kecamatan Babelan Kabupaten Bekasi. Untuk menggali kendala apa saja yang terjadi pada proses pembelajaran.

\section{Hasil dan Pembahasan(70\%)}

\section{A. Deskripsi Hasil Penelitian Perbaikan Pembelajaran \\ 1. Hasil Pengolahan Data}

Fokus perbaikan pada mata pelajaran adalah upaya meningkatkan hasil belajar siswa pada mata pelajaran IPA pada materi Alat Pernapasan Pada Manusia dengan menggunakan media gambar sebagai alat peraga di kelas V SDN Babelan Kota 02 Kecamatan Babelan Kabupaten Bekasi.

Dari hasil evaluasi dan pengamtan yang dilakukan selama proses pembelajaran yang penulis temukan didalam kelas, penulis merumuskan kedalam rakapitulasi nilai untuk setiap siswa dari masing-masing siklus serta rata-rata nilai keseluruhan dengan kualifikasi sebagai berikut :
a. $75-100$
: Baik
b. $60-74$
: Cukup
c. $10-59$
: Kurang

\section{Deskripsi Persiklus}

\section{a. Prasiklus}

Kegiatan prasiklus dilakukan sebelum peneliti melakukan penelitian, hal ini dimaksudkan untuk mengetahui sejauh mana hasil belajar siswa pada mata pelajaran IPA sebelum menggunakan media gambar sebagai alat peraga. Kegiatan Prasiklus dilaksanakan pada 05 September 2019 pada kelas V di SDN Babelan Kota 02. Untuk selengkapnya dapat dilihat pada tabelberikut :

Tabel1.DataaktivitasbelajarsiswaPrasiklus

\begin{tabular}{lll}
\hline JenisKeaktifan & $\begin{array}{c}\text { Jumlahsi } \\
\text { swa }\end{array}$ & $\begin{array}{l}\text { Persent } \\
\text { ase (\%) }\end{array}$ \\
\hline $\begin{array}{l}\text { Aktifdalampembel } \\
\text { ajaran }\end{array}$ & - & - \\
\hline Membuatcatatan & 22 & 100 \\
\hline
\end{tabular}

\begin{tabular}{lll}
\hline $\begin{array}{l}\text { Memperhatikanpen } \\
\text { jelasan }\end{array}$ & 4 & 18,18 \\
\hline Bekerjasama & - & - \\
\hline Bertanya & - & - \\
\hline
\end{tabular}

Hasil Prasiklus pada pembelajaran IPA kelas V di SDN Babelan Kota 02 dapat dilihat pada tabel tersebut, Kriteria ketuntasan Minimal (KKM) untuk mata pelajaran IPA adalah 66, sehingga terdapat 6 siswa yang memperoleh nilai > 66 dan tidak remedial atau $27 \%$ siswa mendapat nilai di atas KKM dan terdapat 16 siswa atau $73 \%$ siswa memperoleh nilai dibawah $\mathrm{KKM}<66$ yang harus mengikuti remedial. Dari hasil yang diperolehtersebutberartiharusdiadakansiklus pertama agar siswadapatmencapaikelulusan, jika pada sikluspertamatingkatkelulusansiswamasihre ndah, makaakandiadakansikluskedua.

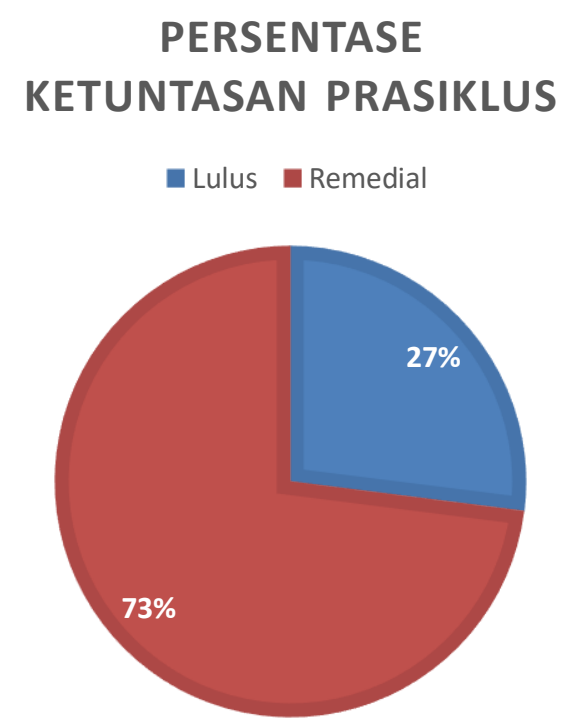

Diagram1. Hasil pembelajaransiswakelas V pada matapelajaran IPA pada prasiklus

\section{b. Siklus 1}

Pelaksanaan perbaikan dan observasi tindakan pertama dilaksanakan pada hari Kamis, 19 September 2019 dari pukul 09.30 sampai dengan pukul 10.40 berlokasi di ruang kelas V SDN Babelan Kota 02, 
Jurnal Edumaspul, 4 (1), 2020 - 345

(Dedi Sulaeman, Muhammad Yusuf Saputro)

pada kegiatan ini penulis mendapatkanhasilpembelajaransebagaiberik ut :

Tabel2.Data aktivitasbelajarsiswa

Siklus 1

\begin{tabular}{lll}
\hline JenisKeaktifan & $\begin{array}{c}\text { Jumlahs } \\
\text { iswa }\end{array}$ & $\begin{array}{c}\text { Persentase } \\
(\%)\end{array}$ \\
\hline $\begin{array}{l}\text { Aktifdalampemb } \\
\text { elajaran }\end{array}$ & 5 & 27,72 \\
\hline Membuatcatatan & 22 & 100 \\
\hline $\begin{array}{l}\text { Memperhatikan } \\
\text { penjelasan }\end{array}$ & 12 & 54,54 \\
\hline $\begin{array}{l}\text { Bekerjasama } \\
\text { Bertanya }\end{array}$ & 4 & - \\
\hline
\end{tabular}

Dari data pada tabel tersebut dapat dilihat adanya peningkatan aktifitas belajar siswa pada siklus I walaupun, masih ada beberapa kelemahan dan kekurangan yang terjadi pada siklus I, yaitu masih banyaknya siswa yang tidak berani dalam bertanya ketika pelajaran berlangsung dan ketika mereka mengalami kesulitan dalam proses pembelajaran.

Setelah melakukan siklus I penulis mendapatkan data bahwa pada pembelajaran IPA kelas $\mathrm{V}$ di SDN Babelan Kota 02 dapat dilihat pada tabel tersebut, Kriteria ketuntasan Minimal (KKM) untuk mata pelajaran IPA adalah 66, sehingga terdapat 14 siswa yang memperoleh nilai $>66$ dan tidak remedial atau 63,6 \% siswa mendapat nilai di atas KKM dan terdapat 8 siswa atau 36,3\% siswa memperoleh nilai dibawah KKM $<66$ yang harus mengikuti remedial. Dari hasil yang diperoleh tersebut berarti harus diadakan siklus kedua.

\section{PERSENTASE \\ KETUNTASAN SIKLUS I}

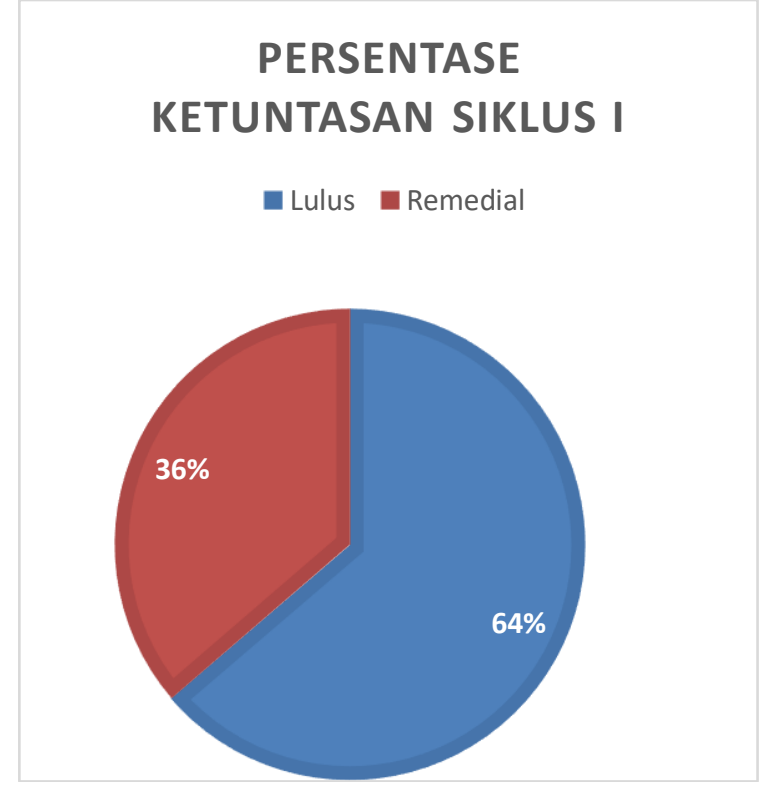

Diagram 2. GrafikSiklus 1

\section{c. Siklus II}

Pelaksanaan pada siklus ke II ini menggunakan media gambar yang lebih baik dan jelas dari siklus I, masih tentang alat pernapasan pada manusia.

Setelah melaksanakan perbaikan pembelajaran pada sikluske II, seluruhpesertadidikberhasilmendapatkannil ai di atas KKM ( >66)

\section{PERSENTASE KETUNTASAN SIKLUS II}

- Lulus Remedial

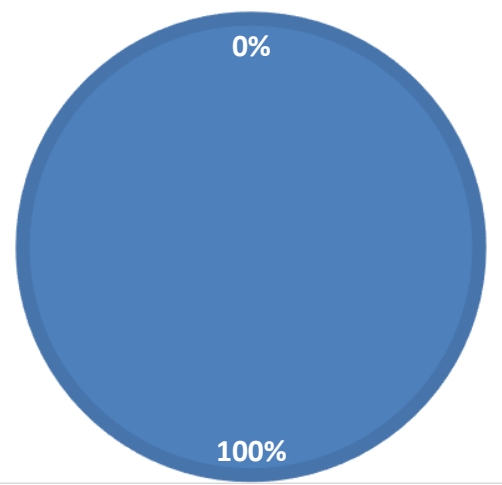

Diagram 3.Grafik Siklus II 
Jurnal Edumaspul, 4 (2), 202 - 346

(Dedi Sulaeman, Muhammad Yusuf Saputro)

a. Observasi

Pada perbaikan pembelajaran siklus II observer mengadakan pengamatan aktifitas siswa dan peneliti hasil dari observasi dapat dilihat pada tabel dibawah ini.

Tabel3. Data aktivitasbelajarsiswaSiklus II

\begin{tabular}{|c|c|c|}
\hline JenisKeaktifan & $\begin{array}{l}\text { Jumlahsi } \\
\text { swa }\end{array}$ & $\begin{array}{l}\text { Persent } \\
\text { asi }(\%)\end{array}$ \\
\hline $\begin{array}{l}\text { Aktifdalampembela } \\
\text { jaran }\end{array}$ & 13 & 59,09 \\
\hline Membuatcatatan & 22 & 100 \\
\hline $\begin{array}{l}\text { Memperhatikanpen } \\
\text { jelasan }\end{array}$ & 22 & 100 \\
\hline Bekerjasama & - & - \\
\hline Bertanya & 13 & 59,09 \\
\hline
\end{tabular}

Berdasarkan dari tabel tersebut dapat diketahui bahwa adanya peningkatan aktifitas belajar siswa dan peningkatan itu terlihat sangat signifikan dari hasil proses pembelajaran sebelumnya hal ini dapat dilihat dari berbagai aspek penilaian.

\section{Pembahasan Hasil Penelitian Perbaikan Pembelajaran}

Pembahasan dalam penelitian ini sekaligus menjawab pertanyaan peneliti, berdasarkan pengamatan yang dilakukan selama observasi, kegiatan pembelajaran menunjukan bahwa siswa lebih banyak pasif dan guru yang banyak beraksi, padahal proses pembelajaran yang efektif adalah proses pembelajaran yang terjadi dua arah antara siswa gan guru, sehingga terjadi interaksi yang lebih aktif.

Atas dasar inilah perlu dilakukannya perbaikan-perbaikan dalam setiap proses pembelajaran. Tindakan awal yang dilakukan peneliti adalah bagaimana caranya agar proses pembelajaran IPA dengan materi alat pernapasan manusia di kelas V semester satu di SDN Babelan Kota 02 dengan menggunakan media gambar sebagai alat peraga. Maksud dari penggunaan media gambar sebagai alat peraga adalah untuk meningkatkan pemahaman siswa terhadap materi tersebut sehingga siswa dapat menuliskan, menyebutkan alat pernapasan pada manusia serta fungsi alat pernapasan pada manusia, juga untuk memberikan pengalaman nyata karena pelajaran IPA tak lepas dari lingkungan sekitar yaitu di kelas V SDN Babelan Kota 02 Kecamatan Babelan Kabupaten Bekasi.

Hasil penilaian mulai dari prasiklus, siklus I dan siklus II. Siswa yang mencapai KKM pada prasiklus sebanyak 6 orang siswa yang mendapat nilai di atas KKM ( 66 ) atau sebesar $27 \%, 14$ siswa yang mendapatkan nilai di atas KKM ( 66 ) pada siklus I atau sebesar $63,6 \%$ dan pada siklus II ternyata seluruh siswa berhasil mendapat nilai di atas KKM atau dengan kata lain $100 \%$ siswa berhasil. 


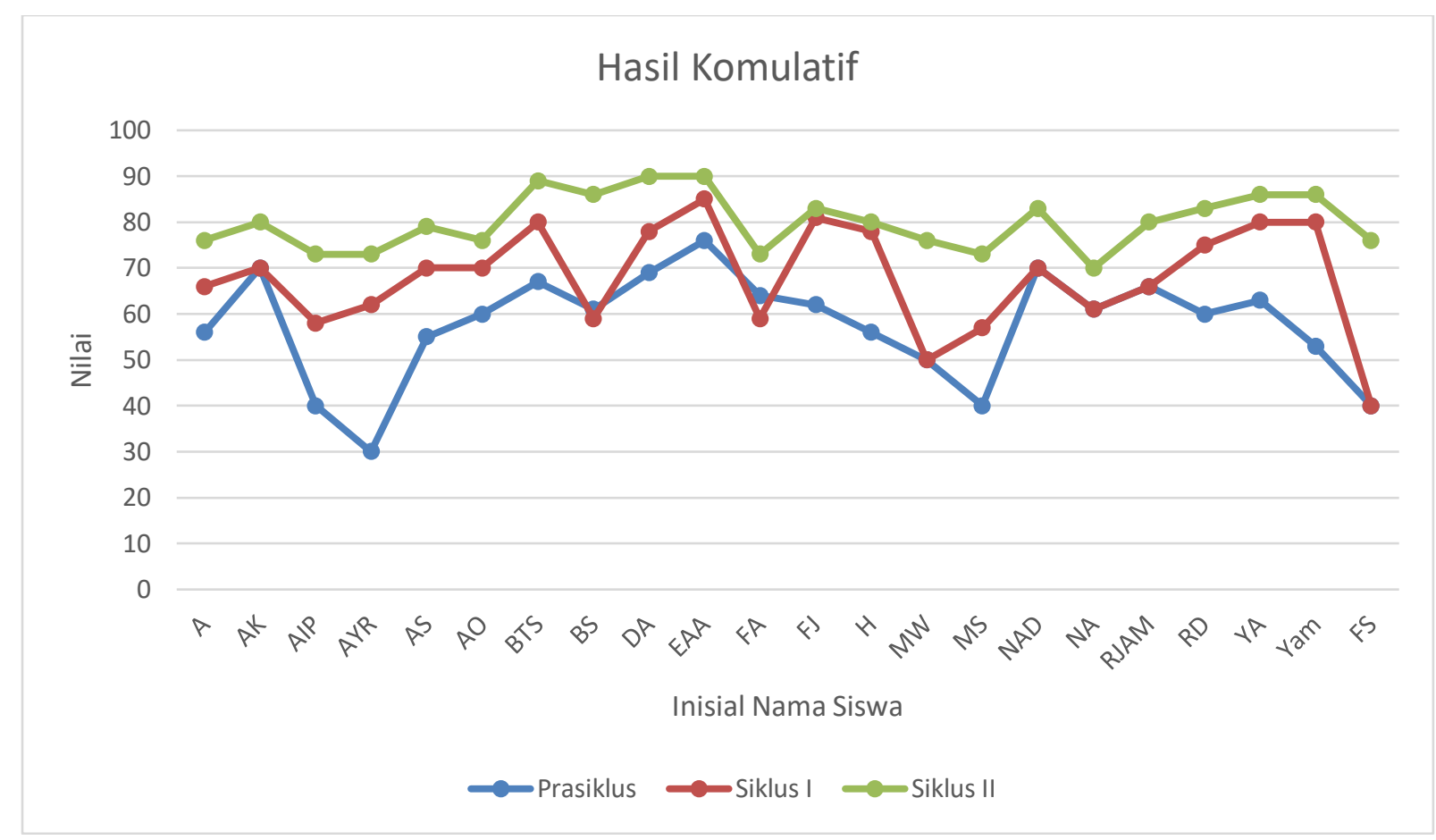

Grafik 1. Nilai Komulatif Hasil Penelitian Perbaikan Pembelajaran

Setelah

mendapatkanhasilevaluasimulaidariPrasiklu s, Siklus I dan siklus II, makadidapatlahnilaisecarakeseluruhantelah mencapai KMM dengan sebaran 17 siswa yang mendapatkannilaibaik dari 75-100 dan 5 orang mendapakannilaicukup dari $66-74$.

\section{Simpulan}

Dengan telah selesainya kegiatan perbaikan ini, berdasarkan tahap pelaksanaan mulai dari Pra Siklus, Siklus I (pertama) sampai dengan Siklus II (kedua). Penulis menarik suatu kesimpulan. Bahwadengan media gambarsebagaialatperagadapatmeningkatka nhasilbelajarsiswakelas $\mathrm{V}$ pada pelajaran IPA.

Setelah melaksanakanSiklus I (pertama) hasilnilai yang diperolehadalah 67,95 ataudenganpersentaseketuntasan 27\%. Siklus II (kedua) mengalamipeningkatanhasilbelajar yang sangatbaikiniterlihatdarihasilnilai yang inididapatdarihasilperbaikanpembelajaran dan bimbingansertapenguatan yang terusmenerusdiberikan oleh guru denganpengalamansecaralagsung dan pembelajarannayat dan bermaknasehinggasiswamenjadiaktifdalam proses pembelajaran.

diperolehsiswa rata-rata 80.04, denganpersentaseketuntasan $100 \%$.

\section{DaftarPustaka}

Hamalik, Oemar. 1992. Psikologi belajar Mengajar. Bandung : Sinar Baru

Gagne. The Condition of Learning and Theory of Instruction, CBS College Publishing, New York:1985

Dimyati dan Mudjiono(2006:3) Proses Pembelajarantersedia di:

http://www.sarjanaku.com/

Dimyati dan Mudjiono(2006:3) Hasil Belajartersediadi:http://www.sarjan aku.com/ 
Jurnal Edumaspul, 4 (2), 202 - 348

(Dedi Sulaeman, Muhammad Yusuf Saputro)

Sardiman. 2006. Interaksi dan MotivasiBelajarMengajar. Jakarta: Raja GrafindoPersada.

Sardiman (1994:24) diunduh 20 September 2013 dari http://mugironiggi.blogspot.com/

Heinich, Robert; Molenda, Michael; Russel, James D. \& Smaldino, Sharon E. (1996). Instructional Media and Technology for Learning. New Jersey: Prentice-Hall.

Marisa, dkk. (2011). Komputer dan Media Pembelajaran. Jakarta: Universitas Terbuka.

De Potter, B; Reardon, M.; \& SingerNourie, S. (1999). Quantum Teaching: Mempraktekan Quantum Learning di Ruang-ruang Kelas. Jakarta: Mizan Media Utama.

Depdiknas. (2001). Kamus Besar Bahasa Indonesia. Jakarta Balai Pustaka.
Sudjana, Nana. 2001. Penilaian Hasil Proses Belajar Mengajar. Bandung: Remaja Rosdakarya.

Abdullah (1998:23). Pengertian IPA dan Perkembangannya. Diunduh 20 September 2013. http://zaifbio.wordpress.com/2010/0 4/29/pengertian-pendidikan-ipadan-perkembangannya.

\section{Profil Penulis}

Dedi Sulaeman, lelaki kelahiran Bekasi 16 Agustus 1985 ini adalah seorang guru sekolah dasar di SDN Babelan Kota 02, dan sedang menempuh jenjang pendidikan S-2 di Program Studi Magister Pendidikan Bahasa Indonesia Universitas Muhammadiyah Prof. DR. HAMKA, di Jakarta.

Muhammad Yusuf Saputro, lelaki kelahiran Rembang 3 Agustus 1994 iniadalah mahasiswa Sekolah Pascasarjana Universitas Muhammadiyah Prof. DR. HAMKA Program Studi Magister Pendidikan Bahasa Indonesia, sekaligus guru bahasa Indonesia di SMPS Pah Tsung Jakarta, dan menjabat sebagai wakil kepala sekolah bidang kurikulum. 